\title{
The 11-item Medication Adherence Reasons Scale: reliability and factorial validity among patients with hypertension in Malaysian primary healthcare settings
}

\author{
Razatul Shima ${ }^{1,3}$, MPH, MBBS, Hairi Farizah ${ }^{1,2}$, PhD, Hazreen Abdul Majid ${ }^{1,2}$, PhD
}

INTRODUCTION The aim of this study was to assess the reliability and validity of a modified Malaysian version of the Medication Adherence Reasons Scale (MAR-Scale).

METHODS In this cross-sectional study, the 15-item MAR-Scale was administered to 665 patients with hypertension who attended one of the four government primary healthcare clinics in the Hulu Langat and Klang districts of Selangor, Malaysia, between early December 2012 and end-March 2013. The construct validity was examined in two phases. Phase I consisted of translation of the MAR-Scale from English to Malay, a content validity check by an expert panel, a face validity check via a small preliminary test among patients with hypertension, and exploratory factor analysis (EFA). Phase II involved internal consistency reliability calculations and confirmatory factor analysis (CFA).

RESULTS EFA verified five existing factors that were previously identified (i.e. issues with medication management, multiple medications, belief in medication, medication availability, and the patient's forgetfulness and convenience), while CFA extracted four factors (medication availability issues were not extracted). The final modified MAR-Scale model, which had 11 items and a four-factor structure, provided good evidence of convergent and discriminant validities. Cronbach's alpha coefficient was $>0.7$, indicating good internal consistency of the items in the construct. The results suggest that the modified MAR-Scale has good internal consistencies and construct validity.

CONCLUSION The validated modified MAR-Scale (Malaysian version) was found to be suitable for use among patients with hypertension receiving treatment in primary healthcare settings. However, the comprehensive measurement of other factors that can also lead to non-adherence requires further exploration.

Keywords: adherence, compliance, factor analysis, scale

\section{INTRODUCTION}

Hypertension is the leading global risk for mortality and is responsible for $13 \%$ of deaths worldwide; other risks include tobacco use $(9 \%)$, high blood glucose $(6 \%)$, physical inactivity $(6 \%)$, and obesity and being overweight (5\%). (1) Despite the availability of effective antihypertensive medication, only $46 \%$ of patients with hypertension achieve optimum blood pressure control; the rest fail to do so due to poor adherence to antihypertensive treatment. ${ }^{(2)}$ Medication adherence is a major concern in healthcare research, especially in the management of chronic conditions, such as hypertension, for which drug treatment is crucial in preventing cardiovascular mortality and morbidity. ${ }^{(3)}$ Poor adherence has been shown to affect blood pressure control negatively. ${ }^{(4)}$

The 2010 National Health Morbidity Survey reported that the prevalence of individuals with known hypertension in Malaysia was $12.8 \%{ }^{(5)}$ an increasing trend was observed when the results of this survey were compared with those of previous surveys. Among the patients with known hypertension, $78.4 \%$ claimed that they were on on oral antihypertensive medications within the past two weeks and $53.2 \%$ had sought treatment at government primary healthcare clinics. ${ }^{(4,5)}$ The rate of medication adherence was found to be low among patients with hypertension receiving treatment in primary care settings; ${ }^{\left({ }^{(6)}\right.}$ A Malaysian study reported a $53.4 \%$ adherence rate. $^{(7)}$
Different tools have been used to evaluate and assess patient adherence to medication, as there is no single goldstandard measurement of patient adherence to medication. ${ }^{(8,9)}$ In developing countries such as Malaysia, information on patient adherence to medication is often derived from self-administered health questionnaires because such research instruments are comprehensive, practical and inexpensive. ${ }^{(9)}$ The most widely used self-reporting measures of medication adherence for hypertension are the Morisky Medication Adherence Scale $(\mathrm{MMAS})^{(10,11)}$ and the Hill-Bone Compliance to Medication Scale. ${ }^{(12)}$ In the MMAS, non-adherence is defined as the intentional or unintentional (e.g. from forgetfulness or carelessness) cessation of medications, whether it is due to the patient feeling better or feeling worse. The Hill-Bone Compliance to Medication Scale addresses the barriers and self-efficacy of patients in their compliance to prescribed medications. In addition to the reasons in the two aforementioned scales, other important reasons for patient non-adherence to antihypertensive medications can be found in the literature. We opine that if more reasons were included, the measure of medication non-adherence would be better able to identify and quantify the contributing factors, and thus improve the measures taken to ameliorate non-adherence.

The aim of the present study was to describe the reliability and construct validity of the Malaysian version of the 15-item

${ }^{1}$ Department of Social and Preventive Medicine, ${ }^{2}$ Centre for Population Health, Faculty of Medicine, University of Malaya, ${ }^{3}$ Ministry of Health, Malaysia 
Medication Adherence Reasons Scale (MAR-Scale). This study is the first step in the development of the MAR-Scale for use in patients with hypertension in Malaysia. The MAR-Scale was originally developed from a literature review of studies on medication adherence from 1966 to $2002 .{ }^{(13)}$ In that review, the ten most frequently reported reasons for non-adherence were identified. Subsequently, five other frequently reported reasons were identified and added to the MAR-Scale, resulting in the 15 -item version. ${ }^{(14,15)}$ In comparison with the MMAS, the MAR-Scale was found to be more effective in identifying non-adherents from adherents. ${ }^{(14)}$

\section{METHODS}

The MAR-Scale consists of five domains and 15 items (Table I). In the questionnaire used in the present study, participants were asked to indicate how often they had been non-adherent to their medications for each of the reasons, using a 5-point Likert scale ( $1=$ none of the time, $5=$ all of the time). ${ }^{(16)}$ None of the items were reversely coded, i.e. all the items in the MAR-Scale were scored on the same rating scale - higher numbers indicate a higher degree of non-adherence to antihypertensive medication.

Ethics clearance for the present study was obtained from the Ministry of Health, Malaysia (NMRR-12-625-12500), and the Ethics Committee of University Malaya, Malaysia (Committee/ IRB Reference No. 914.5). This cross-sectional validation study was conducted in two phases. Translation of the English version of the MAR-Scale into the Malay language, content validation of the translated Malay version by an expert panel, face validation via a preliminary test among a small group of patients with hypertension and exploratory factor analysis (EFA) were conducted in Phase I. Confirmatory factor analysis (CFA) and internal consistency reliability calculations were carried out in Phase II. EFA was done to show the underlying structures, while CFA was done to confirm whether the items adequately measured the underlying concept. ${ }^{(17)}$ The sample size used for EFA and CFA was based on Comrey and Lee's 'very good to excellent' category, which stated that there must be at least 10-15 subjects per item. ${ }^{(18)}$

In Phase I, the original English version of the MAR-Scale was translated into Malay, the official language of Malaysia (this translated version will hereafter be referred to as the Malaysian version of the MAR-Scale). Translation was done independently by two bilingual persons - a graduate school teacher and a public health specialist. Backward translation of the Malaysian version into the English language was undertaken by two bilingual public health specialists. The specialists were blinded to the original English version of the MAR-Scale.

Content validity of the scale was assessed to examine whether the items in the scale were representative of the reasons for nonadherence to antihypertensive medication. This was done with the help of three experts - a family medical specialist, an internal medicine specialist and a public health specialist. They ensured that the Malaysian version of the MAR-Scale retained the same meaning as the original. A pilot test on patients with hypertension was also conducted to assess the face validity of the Malaysian version, in terms of clarity of language and the time taken to complete the questionnaire. Following these evaluations, all 15
Table I. Description of the 15 items in the Medication Adherence Reasons Scale.

\begin{tabular}{|c|c|c|}
\hline Domain & $\begin{array}{l}\text { No. of } \\
\text { items }\end{array}$ & Item description \\
\hline $\begin{array}{l}\text { Management } \\
\text { issues }\end{array}$ & 4 & $\begin{aligned} \text { K15: } & \text { Problems opening medication } \\
& \text { containers } \\
\text { K9 : } & \text { Embarrassment in taking } \\
& \text { medications } \\
\text { K2 : } & \text { Difficulty swallowing } \\
& \text { medications } \\
\text { K4 : } & \text { Uncertainty about proper } \\
& \text { medication administration }\end{aligned}$ \\
\hline $\begin{array}{l}\text { Multiple } \\
\text { medication } \\
\text { issues }\end{array}$ & 3 & $\begin{aligned} \text { K14: } & \text { Concerns about the long-term } \\
& \text { effects of medications } \\
\text { K7 : } & \text { Consumption of too many } \\
& \text { medications } \\
\text { K3 : } & \text { Cost of medications }\end{aligned}$ \\
\hline $\begin{array}{l}\text { Belief issues with } \\
\text { medications }\end{array}$ & 4 & $\begin{array}{l}\text { K10: Ineffective medications } \\
\text { K11: Side effects/fear of side effects } \\
\text { K12: Unnecessary medications } \\
\text { K13: Medication cessation to see if it } \\
\quad \text { is still needed }\end{array}$ \\
\hline Availability issues & 2 & $\begin{array}{l}\text { K1 : Medications unavailable in the } \\
\text { pharmacy } \\
\text { K6 : End of medication supply due } \\
\text { to busy schedule }\end{array}$ \\
\hline $\begin{array}{l}\text { Forgetfulness and } \\
\text { inconvenience } \\
\text { issues }\end{array}$ & 2 & $\begin{aligned} \text { K5 : } & \text { Forgetfulness in taking } \\
& \text { medications due to busy } \\
& \text { schedule } \\
\text { K8: } & \text { Inconvenience in taking } \\
& \text { medications as prescribed }\end{aligned}$ \\
\hline
\end{tabular}

items included in the questionnaire were found to be suitable, relevant and important.

The specially developed 15-item questionnaire was then administered to four government primary healthcare clinics in the Hulu Langat (Bangi and Semenyih Health Clinics) and Klang (Meru and Kapar Health Clinics) districts in Selangor, Malaysia. These clinics serve patients ranging from those with a low-income socioeconomic status to those with an affluent, middle-income socioeconomic status. Between December 2012 and end-March 2013, patients with hypertension who were waiting for their appointments at the chronic diseases clinics were approached with information sheets and informed consent forms. The inclusion criteria were as follows: (a) had a diagnosis of essential hypertension for at least six months; (b) of Malaysian nationality; (c) aged above 18 years; and (d) able to read and understand the English and Malay languages. Patients who agreed to participate in the study were given the self-administered questionnaire, which takes about 15 minutes to complete. Out of the 220 patients with hypertension approached in Phase I, 185 participated in EFA. For CFA in Phase II, 480 of the 580 patients with hypertension who were approached participated in the study.

Analyses were performed using IBM SPSS Statistics version 19 (IBM Corp, Armonk, NY, USA) and IBM SPSS Amos version 21 (IBM Corp, Armonk, NY, USA). Descriptive analyses were performed to obtain the frequencies, proportions, means and standard deviations. Estimation maximisation methods were used to determine missing values. To check for multivariate outliers and to test whether values were missing completely at random 
Table II. Data on the administration of the Medication Adherence Reasons Scale (Malaysian version) in health clinics.

\begin{tabular}{lccc}
\hline Analysis & $\begin{array}{c}\text { No. of } \\
\text { patients } \\
\text { approached }\end{array}$ & $\begin{array}{c}\text { No. of patients } \\
\text { who agreed to } \\
\text { participate }\end{array}$ & $\begin{array}{c}\text { Response } \\
\text { rate (\%) }\end{array}$ \\
\hline EFA & 220 & 185 & 84.1 \\
CFA & 580 & 480 & 82.8 \\
Total & 800 & 665 & 83.1 \\
\hline
\end{tabular}

CFA: confirmatory factor analysis; EFA: exploratory factor analysis

Table III. Demographic data of the respondents $(n=665)$.

\begin{tabular}{|c|c|}
\hline Characteristic & No. (\%) \\
\hline Age* (yr) $^{*}$ & $52.0 \pm 8.73$ \\
\hline \multicolumn{2}{|l|}{ Gender } \\
\hline Male & $369(55.5)$ \\
\hline Female & $296(44.5)$ \\
\hline \multicolumn{2}{|l|}{ Ethnicity } \\
\hline Malay & $379(57.0)$ \\
\hline Chinese & $129(19.4)$ \\
\hline Indian & $148(22.3)$ \\
\hline Others & $9(1.4)$ \\
\hline \multicolumn{2}{|l|}{ Marital status } \\
\hline Married & $552(83.0)$ \\
\hline Widowed & $58(8.7)$ \\
\hline Divorced & $31(4.7)$ \\
\hline Never married & $20(3.0)$ \\
\hline Separated & $4(0.6)$ \\
\hline \multicolumn{2}{|l|}{ Educational level (\%) } \\
\hline Secondary & $286(43.0)$ \\
\hline Primary & $157(23.6)$ \\
\hline Post-secondary certification/qualification & $97(14.6)$ \\
\hline No formal education & $82(12.3)$ \\
\hline University & $38(5.7)$ \\
\hline Others & $5(0.8)$ \\
\hline \multicolumn{2}{|l|}{ Occupation } \\
\hline Housewife & $197(29.6)$ \\
\hline Private sector employee & $172(25.9)$ \\
\hline Self-employed & $101(15.2)$ \\
\hline Government sector retiree & $61(9.2)$ \\
\hline Civil servant & $53(8.0)$ \\
\hline Private sector retiree & $49(7.4)$ \\
\hline Unemployed & $26(3.9)$ \\
\hline Student & $1(0.2)$ \\
\hline Others & $5(0.8)$ \\
\hline
\end{tabular}

* Data presented as mean \pm standard deviation

(MCAR), Roderick JA Little's chi-square statistic was used. ${ }^{(19,20)}$ This test reveals a nonsignificant p-value that is MCAR, i.e. the 'missingness' does not depend on the values of the variables in the data set that is being analysed. ${ }^{(17,21)}$ Mahalanobis distance was used to remove multivariate outliers prior to analysis. ${ }^{(17)}$

\section{RESULTS}

The overall response rate in the present validation study was $83.1 \%$ (Table II). The demographics of the respondents are shown in Table III.
Table IV. Results of Bartlett's test of sphericity and Kaiser-Meyer-Olkin test for the 15-item correlation matrix.

\begin{tabular}{lc}
\hline Test & Result \\
\hline Kaiser-Meyer-Olkin measure of sampling adequacy & 0.637 \\
Bartlett's test of sphericity & \\
Approximate chi-square & 682.717 \\
Degrees of freedom & 105 \\
p-value & $<0.001$ \\
\hline
\end{tabular}

Table V. Communalities in the 15 items of the Medication Adherence Reasons Scale (Malaysian version).

\begin{tabular}{lcc}
\hline Item & Initial & Extraction* \\
\hline K1 & 0.172 & 0.411 \\
K2 & 0.406 & 0.515 \\
K3 & 0.498 & 0.701 \\
K4 & 0.321 & 0.291 \\
K5 & 0.451 & 0.801 \\
K6 & 0.239 & 0.313 \\
K7 & 0.485 & 0.602 \\
K8 & 0.436 & 0.456 \\
K9 & 0.545 & 0.690 \\
K10 & 0.570 \\
K11 & 0.567 & 0.181 \\
K12 & 0.202 & 0.449 \\
K13 & 0.439 & 0.789 \\
K14 & 0.601 & 0.218 \\
K15 & 0.325 & 0.289 \\
\hline
\end{tabular}

*Extraction method: principal axis factoring

A total of 185 respondents were involved in EFA. To justify performing the factor analysis, Bartlett's test of sphericity and Kaiser-Meyer-Olkin (KMO) test were done to determine whether there were sufficient significant correlations among the items. Table IV shows that the results of Bartlett's test of sphericity (chisquare value) was highly significant $(p<0.001)$, indicating that the 15 -item correlation matrix was not an identity matrix. In addition, the KMO value of 0.637 met Kaiser's 'middling criteria', ${ }^{(22)}$ which is $>0.6 .{ }^{(23)}$ Measures of sampling adequacy ranged from 0.45 (for item K8) to 0.72 (for item K12), indicating that there were no problems with multicollinearity in the correlation matrix (i.e. no $r \geq 0.80$ ). ${ }^{(23)}$ These findings show that correlations between the individual items were strong enough and that the correlation matrix was factorable.

The number of initial factors was determined via principal axis factoring (PAF), examination of the communalities, eigenanalysis and examination of the scree plot. PAF, rather than principal component analysis (PCA), was used as an extraction method because the former provides a better estimate of the correlations; PAF includes errors of measurement, while PCA does not separate errors of measurement from shared variance. ${ }^{(24)}$ Oblique rotation, namely direct oblimin, was used as the rotation method because this method assumes that the factors are correlated. Although orthogonal rotations often produce simple solutions, these rotations rest on the critical assumption that the factors, or subscales of interest, are uncorrelated with one another; this 
Table VI. Total variance explained by principal axis factoring of the 15 items in the Medication Adherence Reasons Scale (Malaysian version).

\begin{tabular}{|c|c|c|c|c|c|c|c|}
\hline \multirow[t]{2}{*}{ Factor } & \multicolumn{3}{|c|}{$\begin{array}{c}\text { Initial } \\
\text { eigenvalues }\end{array}$} & \multicolumn{3}{|c|}{$\begin{array}{l}\text { Extraction* sums of } \\
\text { squared loadings }\end{array}$} & \multirow{2}{*}{$\begin{array}{c}\begin{array}{c}\text { Rotation sums of } \\
\text { squared loadings }\end{array} \\
\text { Total }\end{array}$} \\
\hline & Total & $\%$ of variance & Cumulative $\%$ & Total & $\%$ of variance & Cumulative \% & \\
\hline 2 & 2.037 & 13.579 & 32.415 & 1.549 & 10.326 & 26.160 & 1.591 \\
\hline 3 & 1.867 & 12.447 & 44.862 & 1.452 & 9.678 & 35.839 & 1.788 \\
\hline 4 & 1.675 & 11.170 & 56.032 & 1.258 & 8.384 & 44.223 & 1.344 \\
\hline 5 & 1.218 & 8.123 & 64.154 & 0.645 & 4.300 & 48.523 & 0.922 \\
\hline 6 & 0.944 & 6.294 & 70.448 & - & - & - & - \\
\hline 7 & 0.793 & 5.285 & 75.732 & - & - & - & - \\
\hline 8 & 0.720 & 4.800 & 80.532 & - & - & - & - \\
\hline 9 & 0.670 & 4.464 & 84.996 & - & - & - & - \\
\hline 10 & 0.573 & 3.821 & 88.817 & - & - & - & - \\
\hline 12 & 0.429 & 2.863 & 94.824 & - & - & - & - \\
\hline 13 & 0.300 & 2.001 & 96.826 & - & - & - & - \\
\hline 14 & 0.276 & 1.840 & 98.665 & - & - & - & - \\
\hline 15 & 0.200 & 1.335 & 100.000 & - & - & - & - \\
\hline
\end{tabular}

*Extraction method: principal axis factoring. ${ }^{\dagger}$ When factors are correlated, sums of squared loadings cannot be added to obtain a total variance.

Table VII. Pattern matrix of the 15 items of the Medication Adherence Reasons Scale (Malaysian version) showing items with low loadings, namely K11 and K14.

\begin{tabular}{lrrrrr}
\hline Item & \multicolumn{5}{c}{ Factor } \\
\cline { 2 - 6 } & \multicolumn{1}{c}{$\mathbf{1}$} & $\mathbf{2}$ & \multicolumn{1}{c}{$\mathbf{3}$} & \multicolumn{1}{c}{$\mathbf{4}$} & \multicolumn{1}{c}{$\mathbf{5}$} \\
\hline K2 & -0.097 & -0.003 & 0.709 & -0.112 & -0.072 \\
K4 & -0.009 & 0.057 & 0.504 & 0.160 & 0.054 \\
K9 & 0.113 & 0.033 & 0.797 & 0.032 & 0.078 \\
K15 & 0.040 & -0.046 & 0.524 & -0.075 & -0.043 \\
K3 & -0.098 & 0.842 & 0.041 & 0.022 & 0.040 \\
K7 & -0.029 & 0.771 & -0.025 & -0.002 & 0.081 \\
K14 & 0.080 & $0.445^{*}$ & 0.006 & -0.047 & -0.092 \\
K10 & 0.681 & 0.002 & 0.060 & 0.016 & 0.187 \\
K11 & $0.409 *$ & 0.050 & -0.108 & -0.003 & 0.018 \\
K12 & 0.629 & -0.022 & 0.167 & -0.009 & 0.008 \\
K13 & 0.913 & -0.055 & 0.001 & -0.026 & -0.123 \\
K1 & -0.031 & -0.084 & -0.011 & -0.078 & 0.655 \\
K6 & 0.088 & 0.109 & 0.006 & 0.065 & 0.497 \\
K5 & -0.021 & 0.008 & -0.033 & 0.900 & -0.065 \\
K8 & 0.000 & -0.050 & 0.011 & 0.674 & 0.007 \\
\hline
\end{tabular}

Note: Extraction was done using principal axis factoring, while rotation was done using oblimin with Kaiser normalisation. *Values had low loading $(<0.5)$ but were included for further evaluation via confirmatory factor analysis; they were subsequently removed in the final model.

assumption is rarely met in healthcare research. Pedhazur et al ${ }^{(25)}$ argued that orthogonal solutions are unrealistic portrayals of sociobehavioural phenomena and that the assumption that factors might be correlated is a reasonable one in health sciences. This is because although the dimensions that are dealt with in health sciences are often conceptually different, they are, nevertheless, correlated dimensions of a construct. ${ }^{(23)}$

The item communalities, or the total amount of variance among the 15 items that can be explained by the extracted factors, are presented in Table V. Eigenanalysis was done by examining

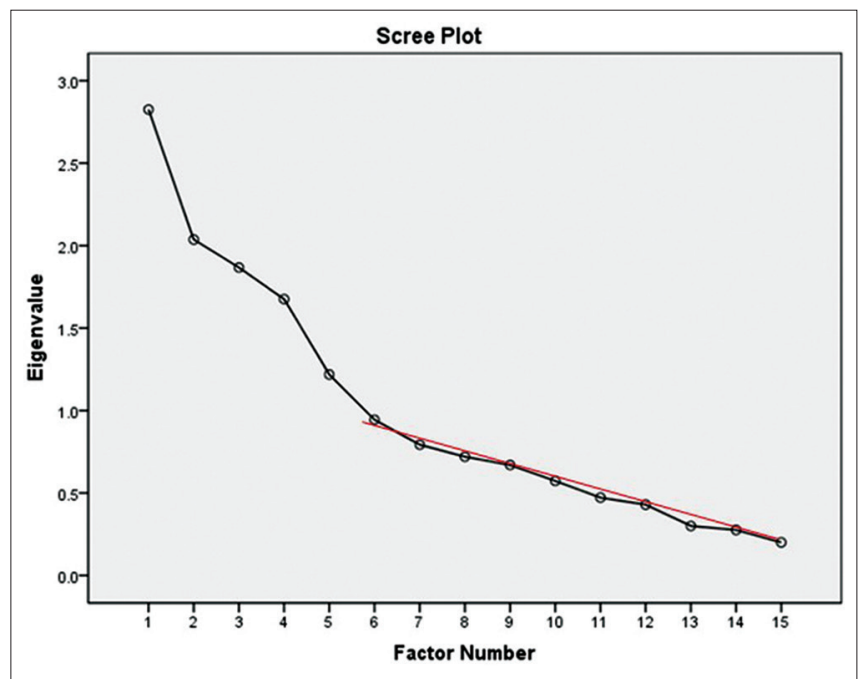

Fig. 1 Scree plot shows the eigenvalues plotted against their principal components. A straight line was drawn through the smaller eigenvalues where a departure from the line occurred.

the eigenvalues (EVs) as shown in Table VI; EVs represent the amount of variance in all of the items that can be explained by a given factor. ${ }^{(23)}$ All factors with EVs $>1$ were selected, according to the Kaiser-Guttman rule, ${ }^{(26,27)}$ in order for the matrix to be positivedefinite and factorable. ${ }^{(18)}$ As depicted in Table VI, five extracted factors met the EV > 1 criterion, with a cumulative percentage of $48.5 \%$ variance extracted by successive factors. ${ }^{(28)}$ There is no fixed threshold to determine the range of the cumulative percentage extracted, although certain percentages have been suggested because the terms usually do not readily apply in the social sciences. ${ }^{(29)}$

In the scree plot (Fig. 1), a straight line was drawn through the smaller EVs where a departure from the line occurred. This point highlights where the debris or break occurs. The point above this debris or break (not including the break itself) indicates 
Table VIII. Principle axis factoring followed by direct oblimin rotation factor loadings of the questionnaire $(\mathrm{n}=185)$.

\begin{tabular}{|c|c|c|c|c|c|c|}
\hline \multirow{2}{*}{$\begin{array}{l}\text { Item } \\
\text { no. }\end{array}$} & \multirow[t]{2}{*}{ Item description } & \multicolumn{5}{|c|}{ Factor loadings } \\
\hline & & $\mathbf{F} 1$ & $\mathbf{F 2}$ & F3 & F4 & F5 \\
\hline $\mathrm{K} 2$ & Difficulty swallowing medications & 0.71 & - & - & - & - \\
\hline K4 & Uncertainty about proper medication administration & 0.54 & - & - & - & - \\
\hline K9 & Embarrassment in taking medications (e.g. when with friends or in a public place) & 0.80 & - & - & - & - \\
\hline K15 & Problems opening medication containers & 0.52 & - & - & - & - \\
\hline K7 & Consumption of too many medications & - & 0.771 & - & - & - \\
\hline K14 & $\begin{array}{l}\text { Concerns about the long-term effects of medications } \\
\text { (e.g. dependency on medications) }\end{array}$ & - & 0.445 & - & - & - \\
\hline K10 & Ineffective medications & - & - & 0.68 & - & - \\
\hline K11 & Side effects/fear of side effects & - & - & 0.41 & - & - \\
\hline K12 & $\begin{array}{l}\text { Unnecessary medications because there is no indication of the } \\
\text { disease (i.e. feeling well without medications) }\end{array}$ & - & - & 0.63 & - & - \\
\hline K13 & Medication cessation to see if it is still needed & - & - & 0.91 & - & - \\
\hline K5 & Forgetfulness in taking medications due to busy schedule & - & - & - & 0.89 & - \\
\hline K8 & $\begin{array}{l}\text { Inconvenience in taking medications as prescribed (e.g. medications increase } \\
\text { frequency of urination and are therefore not taken when away from home) }\end{array}$ & - & - & - & 0.70 & - \\
\hline K1 & Medications unavailable in the pharmacy & - & - & - & - & 0.70 \\
\hline K6 & End of medication supply due to busy schedule & - & - & - & - & 0.51 \\
\hline- & Eigenvalues, cumulative eigenvalues and total variance (\%) by 11 factors & & & & & \\
\hline- & Eigenvalues & 2.83 & 2.04 & 1.87 & 1.68 & 1.22 \\
\hline- & Total percentage and cumulative addition (\%) & 17.41 & 11.50 & 10.65 & 9.23 & 4.80 \\
\hline- & Total variance $(\%)$ by factors & & & & & 53.6 \\
\hline
\end{tabular}

Table IX. Total variance explained with 11 items.

\begin{tabular}{|c|c|c|c|c|c|c|c|}
\hline \multirow[t]{2}{*}{ Factor } & \multicolumn{3}{|c|}{ Initial eigenvalues } & \multicolumn{3}{|c|}{ Extraction* sums of squared loadings } & \multirow{2}{*}{$\begin{array}{c}\begin{array}{l}\text { Rotation sums of } \\
\text { squared loadings }\end{array} \\
\text { Total }\end{array}$} \\
\hline & Total & $\%$ of variance & Cumulative \% & Total & $\%$ of variance & Cumulative \% & \\
\hline 2 & 1.903 & 14.639 & 35.386 & 1.495 & 11.502 & 28.911 & 1.464 \\
\hline 3 & 1.789 & 13.762 & 49.148 & 1.384 & 10.648 & 39.559 & 1.788 \\
\hline 4 & 1.528 & 11.757 & 60.905 & 1.200 & 9.233 & 48.792 & 1.352 \\
\hline 5 & 1.191 & 9.160 & 70.065 & 0.624 & 4.804 & 53.596 & 0.913 \\
\hline 6 & 0.760 & 5.848 & 75.913 & - & - & - & - \\
\hline 7 & 0.700 & 5.382 & 81.296 & - & - & - & - \\
\hline 8 & 0.669 & 5.150 & 86.445 & - & - & - & - \\
\hline 9 & 0.472 & 3.633 & 90.079 & - & - & - & - \\
\hline 10 & 0.444 & 3.417 & 93.496 & - & - & - & - \\
\hline 12 & 0.291 & 2.238 & 98.191 & - & - & - & - \\
\hline 13 & 0.235 & 1.809 & 100.000 & - & - & - & - \\
\hline
\end{tabular}

*Extraction method: principal axis factoring. tWhen factors are correlated, sums of squared loadings cannot be added to obtain a total variance

the number of factors to be retained using the Cattell criteria. ${ }^{(30)}$ Inspection of the scree plot produced a departure from linearity coinciding with the five factors. Further examination of the items' loadings in a pattern matrix (Table VII) was performed in order to increase the percentage of explained variance. Two items, namely items K11 (i.e. side effects/fear of side effects) and K14 (i.e. concerns about the long-term effects of the medications), were then removed. The removal of these items resulted in five factors, but increased the total percentage of cumulative variance to $53.6 \%$, as shown in Tables VIII and IX. Furthermore, analysis using the Monte Carlo-based simulation method was done to compare the observed EVs with those obtained from PCA. A factor or component is retained if the associated EV is larger than the 95th value of the distribution of EVs derived from the random data. ${ }^{(31)}$ The five factors were retained from Horn's parallel analysis (Table X). Phase I findings suggested that the data should be further analysed using CFA for the five factors.

In Phase II, the test-retest reliability was evaluated using the intraclass correlation coefficient (ICC) in a sample of 31 patients. ICC was used instead of kappa because the former is a better measure 
Table X. Distribution of eigenvalues retained from Horn's paralle analysis.

\begin{tabular}{lcc}
\hline Factor & Random eigenvalue & Standard deviation \\
\hline 1 & 1.4571 & 0.0625 \\
2 & 1.3496 & 0.0416 \\
3 & 1.2567 & 0.0397 \\
4 & 1.1766 & 0.0358 \\
5 & 1.1055 & 0.0333 \\
6 & 1.0447 & 0.0284 \\
7 & 0.9865 & 0.0286 \\
8 & 0.9254 & 0.0082 \\
9 & 0.8631 & 0.0297 \\
10 & 0.8038 & 0.0308 \\
11 & 0.7447 & 0.0316 \\
\hline
\end{tabular}

for evaluating data within ratings based on some type of scale, ${ }^{(32)}$ as was the case in this study. ICC values above 0.7 are considered to be an indicator of good reliability. The ICC values for the five subscales (factors) of the Malaysian version of the MAR-Scale ranged between 0.51 and 0.90 (management issues: 0.90; multiple medication issues: 0.70 ; belief issues with the medication: 0.72 ; availability issues: 0.51 ; forgetfulness and convenience issues: 0.78 ), indicating an 'acceptable to good' level of agreement across the four measurements (namely management issues, multiple medication issues, belief issues with the medication, and forgetfulness and convenience issues). However, there was less agreement for the fifth factor (i.e. availability issues). The internal consistency of each factor was calculated using Cronbach's alpha. The overall Cronbach's alpha value was 0.78 and the average values of the five subscales ranged between 0.50 and 0.83 . Only four factors (management issues, multiple medication issues, belief issues with the medication, and forgetfulness and convenience issues) were internally consistent; availability issues was not. It was noted at this stage that availability issues should be removed due to low internal consistency reliabilities, pending confirmation via CFA.

For CFA, a separate sample of 480 patients completed the questionnaire and factor analysis was performed to assess model fitness. A combination of several fit indices were used to assess the model as no agreement on a single gold standard measure exists. ${ }^{(17)}$ As recommended, various fit indices including relative chi-square $\left(\chi^{2} /\right.$ degree of freedom $\left.[\mathrm{df}]\right)$, comparative fit index $(\mathrm{CFI})$, goodness-of-fit index (GFI), adjusted goodness-of-fit index (AGFI), Tucker-Lewis index (TLI), root mean square error of approximation (RMSEA) and standardised root mean square residual were used. It is generally accepted that a $\chi^{2}$ : df ratio $<3$; CFI, GFI, AGFI and TLI values > 0.90; and RMSEA $\leq 0.07$ indicate adequate model fitness. ${ }^{(17)}$ Modification index coefficients were used to check any cross-loadings between items. Model modifications were based on values of the Akaike information criterion for comparing different models. ${ }^{(33)}$ A preliminary model is shown in Fig. 2. Items that have loadings $<0.5$ were removed sequentially. ${ }^{(17)}$ Three items, namely K1 (i.e. unavailable medications in the pharmacy), K11 (i.e. side effects/fear of side effects) and K14 (i.e. concerns about the long-term effects of medications) were removed. The availability issues factor was removed because after the removal of item K1, only item $\mathrm{K} 6$ was left in the factor and it indicated low reliability. The fit indices of the final four-factor model with 11 items indicated good model fit: $\chi^{2}: \mathrm{df}=2.244, \mathrm{CFI}=0.952$, $\mathrm{TLI}=0.933, \mathrm{GFI}=0.969$, and RMSEA $=0.050$ (Fig. 3)

The model was cross-validated with 1,000 bootstrap resample, which yielded a Bollen-Stine p-value of 0.064 (i.e. > 0.05), indicating that the model was valid. The model also demonstrated convergent validity with standardised loadings of $>0.5$. The average variance extracted (AVE) values for the four factors were near 0.5 and the composite reliability was 0.7 . Between the respective constructs, the AVE values were greater than the R-squared values, indicating sufficient discriminant validity. ${ }^{(17)}$

Multi-group analysis was done and factorial invariance was examined to test whether the items in the Malaysian version of the MAR-Scale can be used equivalently across different populations (e.g. with different ethnicity and gender proportions). The degree to which tests or inventories measure a construct in an equivalent fashion, across different groups, was determined. ${ }^{(34)}$ As proposed by Cheung and Rensvold, ${ }^{(35)}$ a difference in $\mathrm{CFI}$ value of $<0.01$ and a p-value $>0.05$ were taken to indicate that factorial invariance was present. The Malaysian version of the MAR-Scale was found to demonstrate sufficient factorial invariance across gender (Table XI).

\section{DISCUSSION}

The results of the present study demonstrated that 11 of the 15 items of the MAR-Scale (Malaysian version) had good reliability and construct validity among patients with hypertension from government primary healthcare clinics in Selangor, Malaysia. As the study only included patients with hypertension who were treated in government primary healthcare clinics, the findings cannot be generalised to the entire hypertensive population in Malaysia. The results obtained may be due to characteristics unique to patients with hypertension who were treated and had follow-ups in government primary healthcare clinics. ${ }^{(36)}$ Nonetheless, the findings of the study may serve as a basis for future studies that wish to compare patients with hypertension attending government primary healthcare clinics with those attending private primary healthcare clinics.

Factorial validation from the present study confirmed a fourfactor structure instead of the original five. This may be due to the different background and culture of the study population. The findings of our study suggest that patients with hypertension face issues such as medication management, multiple medications, belief in medication, forgetfulness and inconvenience. The results are consistent with those of previous studies conducted in other developing countries. ${ }^{(37)}$ In our study, medication availability issues were not found to be a reason for non-adherence, which is similar to that observed in another study conducted in Malaysia. The study reported that poor blood pressure control was not due to medication availability issues or a lack of therapeutic regimens. ${ }^{(38)}$

The present study has several strengths. Four methods of validation were utilised and four primary health clinics in two districts were assessed. The sample size for CFA was large and the overall response rate was good. The findings of this study provide 
Table XI. Factorial invariance across gender.

\begin{tabular}{lccccccc}
\hline Model & $\chi^{2}$ & df & CFI & $\begin{array}{c}\text { Difference in } \\
\text { CFI values }\end{array}$ & $\begin{array}{c}\text { Difference } \\
\text { in } \chi^{2} \text { values }\end{array}$ & $\begin{array}{c}\text { Difference } \\
\text { in df }\end{array}$ & $\begin{array}{c}\text { p-value } \\
\text { I: Configural }\end{array}$ \\
II: Weak factorial invariance & 195.207 & 79 & 0.968 & - & - & - & - \\
III: Strong factorial invariance & 201.266 & 86 & 0.969 & 0.001 & 6.059 & 7 & 0.532 \\
IV: Strict factorial invariance & 217.893 & 96 & 0.967 & 0.001 & 22.686 & 17 & 0.160 \\
\hline
\end{tabular}

CFI: comparative fit index; df: degrees of freedom

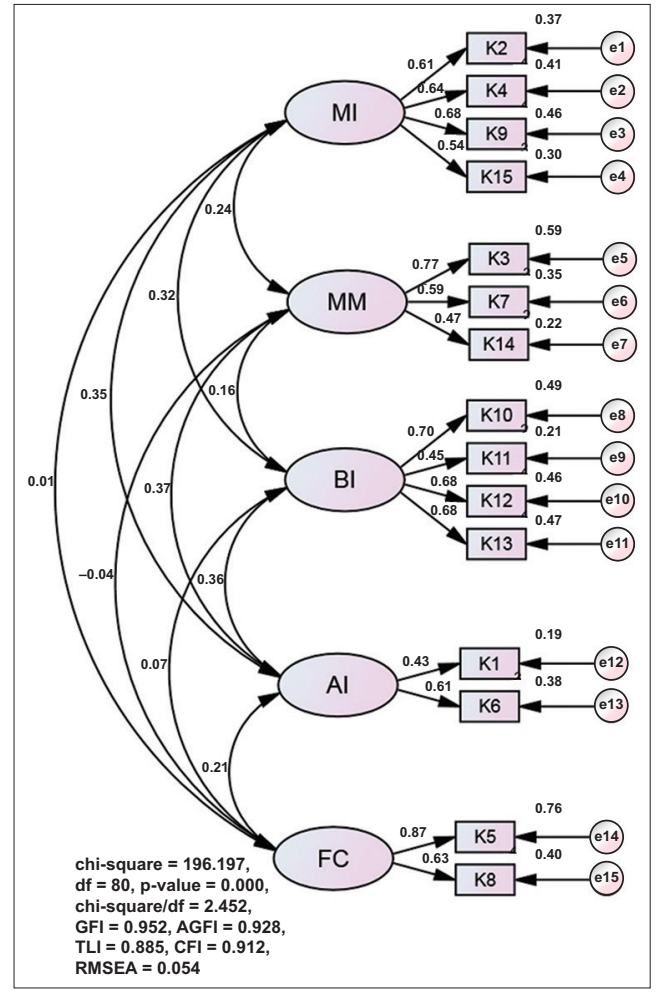

Fig. 2 Factor structure of the preliminary model of the Medication Adherence Reasons Scale (Malaysian version) using confirmatory factor analysis. AGFI: adjusted goodness-of-fit index; Al: availability issues; $\mathrm{BI}$ : belief issues with medications; $\mathrm{CFI}$ : comparative fit index; df: degrees of freedom FC: forgetfulness and convenience issues; GFI: goodness-of-fit index; MI: management issues; MM: multiple medication issues; RMSEA: root mean square error of approximation; TLI: Tucker-Lewis index

initial evidence of the face and content validities, test-retest and internal consistency reliabilities and construct validity of the Malaysian version of the MAR-Scale. Moreover, to the best of our knowledge, the present study is the only validated study conducted among patients with hypertension in Malaysia to understand reasons for non-adherence. However, in the exploratory factorial validation, it is important to note that not all individual measures of sampling adequacy were above $0.6 ;^{(23)}$ although the values of items K3 (i.e. cost of medications; 0.47), K7 (i.e. consumption of too many medications; 0.49), K5 (i.e. forgetfulness in taking medications due to busy schedule; 0.47 ) and K8 (i.e. inconvenience in taking medications as prescribed; 0.45 ) were not above 0.6 , these items were not dropped in the statistical analysis. This is because removing too many items would affect the factor structure of the scale (there would have been too few items left for CFA).

The multi-group analysis results demonstrate sufficient factorial invariance across gender and ethnicity. Further validation studies that compare these factorial validation methods (e.g. EFA

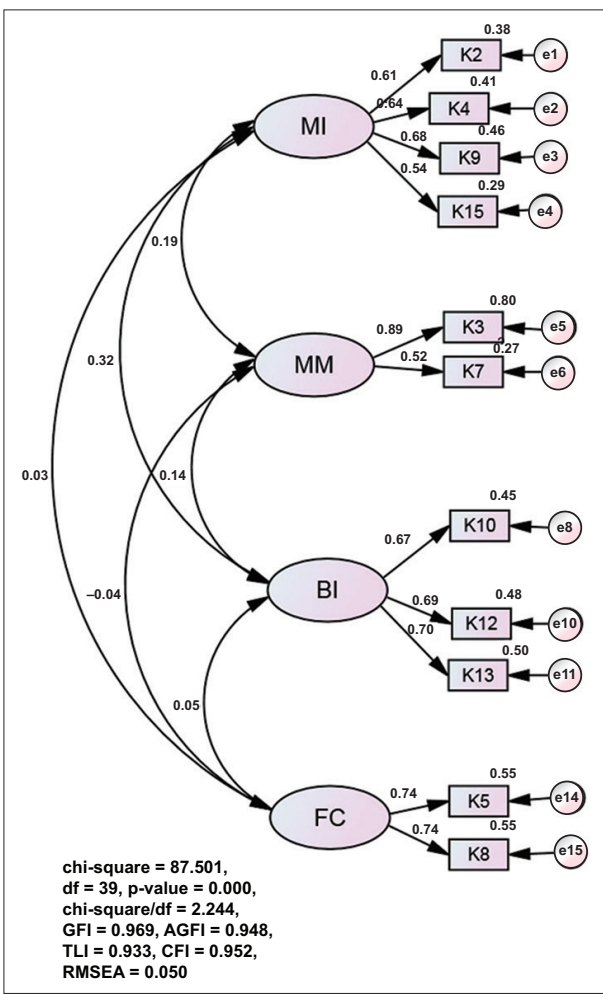

Fig. 3 Factor structure of the final model of the Medication Adherence Reasons Scale (Malaysian version) using confirmatory factor analysis. AGFI: adjusted goodness-of-fit index; Al: availability issues; $\mathrm{BI}$ : belief issues with medications; $\mathrm{CFI}$ : comparative fit index; df: degrees of freedom; FC: forgetfulness and convenience issues; GFI: goodness-of-fit index; MI: management issues; MM: multiple medication issues; RMSEA: root mean square error of approximation; TLI: Tucker-Lewis index

and (FA) with other methods such as the Rasch analysis may be beneficial, because the latter method separates respondent and item properties to ensure that each validated item accounts for each participant's background and level of literacy. Further studies evaluating the use of the Malaysian version of the MAR-Scale in patients with other chronic diseases (e.g. diabetes mellitus and asthma) could be done.

It should be noted that although items might be observed to be statistically significant in the present study, some of these items might be clinically nonsignificant. For example, although side effects/fear of side effects and concerns about the long-term effects of the medications were found to be important reasons for nonadherence in the literature, these two items were excluded from our study. Further qualitative studies may be needed to explore whether each item is an important reason for non-adherence in the present study's group of patients with hypertension. In the future, if more items are found to be associated with non-adherence, they may be added to the scale so that it will be better able to 
identify, quantify and explain the reasons for non-adherence. The items in the scale should also have been tested for predictive validity with regard to blood pressure control, as was done for the self-reported MMAS. ${ }^{(11)}$

The present validation study is an important step in the development of a new tool for measuring self-reported antihypertensive medication non-adherence. It is a clinically meaningful scale that can be used by healthcare providers to measure non-adherence and to identify the reasons for nonadherence. The information derived from the use of this scale can help healthcare providers better understand the reasons for non-adherence among patients with hypertension attending government primary healthcare clinics in Malaysia. With this better understanding, healthcare providers will be better equipped to develop more efficient interventions to promote adherence.

In conclusion, the findings of the present study indicate that the modified scale (i.e. the Malaysian version of the MAR-Scale) is suitable for use and that it is a valuable four-factor, 11-item tool for measuring reasons for non-adherence to antihypertensive medication in primary healthcare settings. However, the comprehensive measurement of other factors that can also lead to non-adherence requires further exploration.

\section{ACKNOWLEDGEMENTS}

We would like to thank the Director General of Health, Malaysia, for granting us permission to publish this study. We also like to thank Dr Elizaberth Jisha Unni, Department of Pharmaceutical Sciences, University of Southern Nevada, USA, for giving us permission to use the original MAR-Scale. Our thanks also goes out to Prof Karuthan Chinna, Department of Social and Preventive Medicine, University of Malaya, for his valuable input and guidance on the statistical aspects of this research, and Dr Hanif bin Zailani, District Health Officer, Hulu Langat District Health Office, Ministry of Health, for his assistance.

\section{REFERENCES}

1. World Health Organization (WHO). Global Health Risks. Mortality and Burden of Disease Attributable to Selected Major Risks. 2009. Available at: http://www.who.int/healthinfo/global_burden_disease/GlobalHealthRisks_ report_full.pdf. Accessed December 12, 2012.

2. Centres for Disease Control and Prevention (CDC 2011). Vital signs: prevalence, treatment, and control of hypertension-United States, 19992002 and 2005-2008. Available at: http://www.cdc.gov/mmwr/preview/ mmwrhtml/mm6004a4.htm. Accessed January 7, 2013.

3. Wong MC, Tam WW, Cheung CS, et al. Drug adherence and the incidence of coronary heart disease- and stroke-specific mortality among 218,047 patients newly prescribed an antihypertensive medication: A fiveyear cohort study. Int J Cardiol 2013 30; 168:928-33.

4. Bramley TJ, Gerbino P, Nightengale B, Frech-Tamas F. Relationship of blood pressure control to adherence with antihypertensive monotherapy in 13 managed care organizations. Journal of managed care pharmacy. J Manag Care Pharm 2006; 12:239-45.

5. Ministry of Health Malaysia. National Health and Morbidity Survey Kuala Lumpur 2011. Kuala Lumpur: Minstry of Health Malaysia, 2011.

6. World Health Organization. Adherence to Long-Term Therapies: Evidence for Action. 2003. Available at: http: whqlibdoc.who.int/ publications/2003/9241545992.pdf. Accessed November 21, 2011.

7. Ramli A, Ahmad NS, Paraidathathu T. Medication adherence among hypertensive patients of primary health clinics in Malaysia. Patient Prefer Adherence 2012; 6:613-22.

8. Vermeire E, Hearnshaw H, Van Royen P, Denekens J. Patient adherence to treatment: three decades of research. A comprehensive review. J Clin Pharm Ther 2001; 26:331-42.

9. Osterberg L, Blaschke T. Adherence to medications. N Engl J Med 2005; 353:487-97

10. Morisky DE, Green LW, Levine DM. Concurrent and predictive validity of a self-reported measure of medication adherence. Med Care 1986; 24:67-74.

11. Morisky DE, Ang A, Krousel-Wood M, Ward HJ. Predictive validity of a medication adherence measure in an outpatient setting. J Clin Hypertens (Greenwich) 2008; 10:348-54.

12. Kim MT, Hill MN, Bone LR, Levine DM. Development and testing of the Hill-Bone Compliance to High Blood Pressure Therapy Scale. Prog Cardiovasc Nurs 2000; 15:90-6.

13. Vik SA, Maxwell CJ, Hogan DB. Measurement, correlates, and health outcomes of medication adherence among seniors. Ann Pharmacother 2004; 38:303-12.

14. Unni EJ. Development of models to predict medication non-adherence based on a new typology [Online]. Available at: http://ir.uiowa.edu/cgi/ viewcontent.cgi?article=1195\&context=etd. Accessed October 8, 2012.

15. Unni EJ, Farris KB. Development of a new scale to measure self-reported medication nonadherence. Res Social Adm Pharm 2009. [Epub ahead of print]

16. Wroe AL. Intentional and unintentional nonadherence: a study of decision making. J Behav Med 2002; 25:355-72.

17. Hair JF Jr, Black WC, Babin BJ, Anderson RE. Multivariate Data Analysis. 7th ed. New York: Prentice Hall, 2009.

18. Comrey AL, Lee HB. A first course in factor analysis. 2nd ed. New Jersey: Psychology Press, 1992.

19. International Business Machines (IBM). IBM SPSS Missing Values 20, 2011 [Online]. Available at: ftp://public.dhe.ibm.com/software/analytics/ spss/documentation/statistics/20.0/en/client/Manuals/IBM_SPSS_Missing_ Values.pdf. Accessed February 25, 2013.

20. Donders AR, van der Heijden GJ, Stijnen T, Moons KG. Review: gentle introduction to imputation of missing values. J Clin Epidemiol 2006; 59:1087-91.

21. Chen HY, Little R. A test of missing completely at random for generalised estimating equations with missing data. Biometrika 1999; 86:1-13.

22. Kaiser HF. An index of factorial simplicity. Psychometrika 1974; 39:31-6.

23. Pett AM, Lackey NR, Sullivan JJ. Making sense of factor analysis: the use of factor analysis for instrument development in health care research. Thousand Oaks: Sage Publications, 2003.

24. Nunnally JC, Bernstein IH. Psychometric theory. 3rd ed. New York: McGraw-Hill, 1994.

25. Pedhazur EJ, Schmelkin. Measurement, design and analysis: an integrated approach. New Jersey: Psychology Press, 1991.

26. Kaiser HF. The application of electronic computers to factor analysis. Educational and Psychology Measurement 1960; 20:141-51.

27. Guttman L. Some necessary conditions for common-factor analysis. Psychometrika 1954; 19:149-61.

28. Gorsuch RL. Factor analysis. New Jersey: Lawrence Erlbaum, 1983.

29. Williams B, Brown T. Exploratory factor analysis: A five-step guide for novices. Australasian J Paramedicine 2010; 8:1-13.

30. Cattell RB. The scree test for the number of factors. Multivariate Behav Res $1966 ; 1: 245-76$.

31. Ledesma RD, Valero-Mora P. Determining the number of factors to retain in EFA: an easy-to-use computer program for carrying out parallel analysis. Prac Ass Res Eval 2007; 12:1-11

32. Lahey MA, Downey RG, Saal FE. Intraclass correlations: There's more there than meets the eye. Psychol Bull 1983; 93:586-95.

33. Hu L, Bentler PM. Cutoff criteria for fit indexes in covariance structure analysis: Conventional criteria versus new alternatives. Struct Equ Modeling 1999; 61:1-55.

34. Byrne BM. Structural equation modeling with AMOS. Basic Concepts, Applications, and Programming. 2nd ed. California: Sage Publications, 2009.

35. Cheung GW, Rensvold RB. Evaluating goodness-of-fit indexes for testing measurement invariance. Struct Equ Modeling 2002; 9:233-55.

36. Grigoryan L, Pavlik VN, Hyman DJ. Predictors of antihypertensive medication adherence in two urban health-care systems. Am J Hypertens 2012; 25:735-8.

37. Saleem F, Hassali M, Shafie A, Atif M. Drug attitude and adherence: a qualitative insight of patients with hypertension. J Young Pharm 2012; 4:101-7.

38. Aziz AM, Ibrahim MI. Medication noncompliance--a thriving problem. Med J Malaysia 1999; 54:192-9. 